\title{
TREINTA AÑOS DE IUS PUBLICUM COMMUNE EUROPEO EN ESPAÑA
}

\author{
Ricardo Alonso García \\ Catedrático de Derecho Administrativo \\ Universidad Complutense de Madrid
}

\begin{abstract}
RESUMEN
El presente trabajo pretende esbozar el proceso de recepción, durante los últimos treinta años y bajo el influjo del derecho de la Unión Europea, de un ius commune de corte público en el ordenamiento español. Dicho ius commune tiene su origen en los principios generales del derecho que el Tribunal de Justicia de la UE ha elaborado a golpe de sentencia recurriendo, como principal fuente de inspiración, a los derechos de los Estados miembros. Principios que han hecho, no obstante, un viaje de ida y vuelta: una vez reconstruidos en síntesis europea, retornan a los ordenamientos de los Estados miembros para vincular a las autoridades públicas tanto cuando actúan como ejecutores del derecho de la Unión, como cuando lo hacen en ámbitos ajenos al radio de acción de la Unión. Para cumplir con el propósito señalado, se han elegido tres ejemplos en este trabajo: el poder/deber del juez nacional de adoptar medidas cautelares, la doctrina de las expectativas legítimas, y el principio de responsabilidad de los Estados miembros por infracción del derecho de la Unión.
\end{abstract}

Palabras clave: ius commune europeo; principios generales del derecho europeo; medidas cautelares; expectativas legítimas; responsabilidad patrimonial de los Estados miembros.

\begin{abstract}
This dissertation briefly examines the process by which a body of common public law has been introduced in the Spanish legal system, over the last 30 years, under the influence of the EU law. The origins of that ius commune can be traced to the general principles recognized and applied by the European Court of Justice. In doing so, the ECJ has drawn first and foremost on common legal principles in the various EU member states. These general principles have taken a round-trip though: once they have been reshaped as a 'European synthesis', they have reenter the Member States legal systems as rules with a far reaching mandatory effect, binding national public bodies not only when they are implementing Union law, but also when their actions lay outside the scope of EU law. In order to explain this course, this paper proceeds through three different examples: the power and duty of national courts to apply interim relief in order to ensure the full effectiveness of EU law, Member State liability for breach of EU law and the doctrine of legitimate expectations.
\end{abstract}

Key words: European Common law; EU general principles; interim measures; legitimate expectation; member State liability. 
En noviembre de 1988, quien escribe estas líneas defendía su tesis doctoral, bajo el título «Hacia un ius publicum commune europeo» ${ }^{1}$, en la Universidad Complutense.

Mi propósito en las siguientes páginas, destinadas a honrar a la $R A P$ con ocasión de sus 200 números, será el de esbozar, con algunos ejemplos extraídos de cada década desde nuestra adhesión, en enero de 1986, a las entonces Comunidades Europeas, el devenir, en el contexto del derecho español, de un ius commune de corte público, cuya funcionalidad, en relación con los sectores de la vida jurídica nacional situados al margen del radio de acción de la hoy Unión Europea, consistiría no en desplazar, suplantándolos, a los ordenamientos de los Estados miembros, sino en actuar como un molde al que éstos se irían acomodando, procediendo dichos Estados, al elaborar y aplicar su ius publicum proprium, a hacerlo no de forma aislada o autónoma, sino a la luz de ese mos europaeus.

Dicho ius commune tendría su origen en los principios generales del derecho elaborados a golpe de sentencia por un Tribunal de Justicia ${ }^{2}$ que tempranamente asumió como herramienta habitual de trabajo la metodología del recurso al derecho de los Estados miembros, prevista en los Tratados a los efectos de configurar el régimen de responsabilidad extracontractual de las Comunidades Europeas ${ }^{3}$.

Así, enfrentado a un problema sobre el que el derecho positivo comunitario - hoy de la Unión- guardaría silencio ${ }^{4}$ o resultaría insuficiente $^{5}$ a los efectos de su solución, el Tribunal de Justicia recurriría

1 Poco después publicada: R. Alonso García (1989), Derecho comunitario, Derechos nacionales y Derecho común europeo, Madrid: Civitas.

2 Al margen de las reflexiones que siguen, quedan intentos más modernos, incluidos los de índole académica, de codificación (cfr., H. Hofmann, J. Ziller, J. P., Schneider, y O. Mir, (2015), Codigo ReNEUAL de procedimiento administrativo de la Union Europea, Madrid: INAP).

3 Según dispone actualmente el párrafo segundo del art. 340 TFUE, el cual reproduce prácticamente la versión original de los Tratados de Roma, «en materia de responsabilidad extracontractual, la Unión deberá reparar los daños causados por sus instituciones o sus agentes en el ejercicio de sus funciones, de conformidad con los principios generales comunes a los Derechos de los Estados miembros».

4 Caso, por ejemplo, del principio de la inderogabilidad singular de las disposiciones generales, fundamentado a su vez en el principio de igualdad ante la ley; principio este de origen romano (legem patere quam fecisti) que, como sostuviera el abogado general Warner, impone que cuando una autoridad pública, mediante un acto normativo, haya establecido reglas generales, si bien es cierto que puede modificar tales reglas mediante un acto normativo posterior, no puede soslayarlas cuando examina casos particulares: cfr. asuntos Ball Bearings, resueltos por Sentencias, todas ellas, de 29 de marzo de 1979.

5 Caso, por ejemplo del principio de motivación, al que el TFUE, en la línea de sus antecesores, dedica su art. 296 sin hacer distinciones entre disposiciones generales y actos de aplicación, y que ha sido matizado por el Tribunal de Justicia en el sentido de intensificar sus exigencias si referido a estos últimos (doctrina que se remonta la Sentencia, dictada en el ámbito Comunidad Europea del Carbón y del Acero, Barge v. Alta Autoridad, de 16 de diciembre de 1963, extendida después al ámbito de la Comunidad Económica Europea en el asunto Beus, de 
a los derechos nacionales, analizando el tratamiento del problema por éstos abordado, como regla general, en términos similares en el ámbito estrictamente interno (habida cuenta de que, en última instancia, tanto el derecho público europeo como los derechos públicos nacionales se inspirarían en la misma filosofía, que no es otra que la búsqueda de un adecuado equilibrio entre las prerrogativas de las autoridades públicas y la esfera jurídica inviolable de los individuos; o lo que es igual, la consecución del «eficaz servicio del interés general con la menor mengua posible de las situaciones jurídicas, igualmente respetables, de los ciudadanos $\left.{ }^{6}\right)$. Y a partir de ese análisis de los derechos nacionales, el Tribunal de Luxemburgo procedería a la construcción de la síntesis europea, a la luz de la especial naturaleza del ordenamiento jurídico comunitario; síntesis que, como señalaba, estaría llamada a revertir a su vez, en un efecto que podríamos denominar boomerang, sobre esos mismos derechos nacionales, tanto en términos vinculantes (en aquellos ámbitos en los que los Estados miembros estarían actuando como brazo ejecutor de la Unión ${ }^{7}$ ) como a modo de ius commune (en ámbitos ajenos al radio de acción de la Unión).

Situándonos a comienzos de la década de los noventa, concretamente el 19 de junio de 1990, el Tribunal europeo de Justicia emitía su Sentencia en el asunto Factortame, trascendental para el ordenamiento jurídico comunitario considerado en su conjunto, y además revolucionaria para el sistema jurídico anglosajón, que estaba en el origen de la

13 de marzo de 1968). Por otro lado, dicho terreno de los actos de aplicación también ha sido, a su vez, objeto de matices por parte del Tribunal. Así, la exigencia de motivación de los actos, predicable con carácter general con independencia del contexto en el que se enmarquen (cfr. asunto Francia v. Comisión, Sentencia de 11 de noviembre de 1987), se acentúa cuando éste tiene carácter sancionador (cfr. asunto Krupp v. Comisión, Sentencia de 12 de noviembre de 1985); o cuando mayor es la discrecionalidad de la que goza la autoridad europea (cfr. asunto Präesident e.a. v. Alta Autoridad, Sentencia de 15 de julio de 1960); o, en fin, cuando, además de la tutela judicial efectiva inherente a la motivación (en la medida en que la motivación "persigue dar una oportunidad a las partes para defender sus derechos»: cfr. asunto Alemania v. Comisión, Sentencia de 4 de julio de 1963), entran en juego otros derechos fundamentales, como por ejemplo el secreto profesional (cuyo levantamiento por la Comisión frente a una alegada confidencialidad exige una previa decisión motivada susceptible de control jurisdiccional: $\mathrm{cfr}$. asuntos Akzo Chemie v. Comisión, Sentencia de 24 de junio de 1986, y SEP v. Comisión, Sentencia de 19 de mayo de 1994), o la igualdad ante la ley conectada con la necesidad de motivar la desviación de una práctica administrativa (cfr. asuntos Louwage v. Comisión, Sentencia de 30 de enero de 1974, y Michael v. Comisión, Sentencia de 1 de diciembre de 1983).

6 E. García de Enterría y T. R. Fernández (2004), Curso de Derecho Admnistrativo I, Madrid: Thomson-Civitas, pág. 53. En parecidos términos, cfr. W. WADE y CH. ForsyTH (2004), Administrative Law, Oxford: Oxford University Press, págs. 4-6.

7 Cfr. Sentencia del Tribunal de Justicia de 27 de septiembre de 1979, asunto Eridiana. 
cuestión prejudicial planteada por la House of Lords a Luxemburgo y que la referida Sentencia venía a responder. Trascendental para el ordenamiento comunitario porque en ella el Tribunal de Justicia completó su doctrina Simmenthal, en el sentido de extender el poder-deber de los jueces nacionales de inaplicar, por su propia autoridad, toda regla jurídica interna, al margen de su rango normativo, contraria al derecho comunitario, al poder-deber de «conceder medidas provisionales para garantizar la plena eficacia de la resolución judicial que debe recaer acerca de la existencia de los derechos invocados con base en el derecho comunitario». Y revolucionaria para el sistema jurídico anglosajón porque con su fallo, el Tribunal de Justicia obligaba a los jueces británicos a descartar «la antigua norma del "common law", según la cual no puede concederse ninguna medida provisional contra la Corona, es decir, contra el Gobierno; norma que había que interpretar en relación con la presunción de que las leyes nacionales son conformes al derecho comunitario, mientras no se haya resuelto acerca de su compatibilidad con este derecho».

Por lo que respecta al ordenamiento jurídico español, el Tribunal Supremo se haría pronto eco de Factortame en su pionero Auto de 17 de febrero de 1991 (que a su vez hacía eco de otro de 20 de diciembre de 1990, del que no existe huella en el buscador de jurisprudencia CENDOJ, pero que fue en su momento comentado por el maestro García de Enterría en el núm. 69 de la REDA).

Varias cuestiones resultan dignas de advertencia al respecto.

En primer lugar, cómo en dicho Auto, al que seguirán muchos otros (cfr., p. e., los de 14 de marzo 1996, 4 de junio de 1997 y 24 de febrero de 1998), el Tribunal Supremo atribuyó al Tribunal de Justicia el principio de que la «necesidad de acudir al proceso para obtener la razón no debe perjudicar a quien tiene la razón», pese a que en ningún momento dicho principio se recogería en la Sentencia misma, sino en las Conclusiones, mucho más elaboradas y matizadas, de su abogado general Tesauro (quien, por lo demás, no ocultaría su malestar ante la futilidad con la que el Tribunal de Justicia abordó finalmente la cuestión - a la que dedicó apenas seis FFJJ_- habida cuenta de que «no se trataba de remover una simple disposición nacional, cual leyecita - leggina - sobre el etiquetaje del agua mineral, sino un principio fundamental del sistema procesal anglosajón» ${ }^{8}$ ). De hecho, una lectura detenida de Factortame

8 G. Tesauro (1992), "Tutela cautelare e Diritto Comunitario», Rivista Italiana di Diritto Pubblico Comunitario, 1, págs. 137-138. Ya antes, a los pocos meses de Factortame, el abogado general se había mostrado crítico con el pronunciamiento del Tribunal; cfr. G. Tesauro (1991), "Corte di Giustizia e Corte Costituzionale», en La Corte Costituzionale tra Diritto interno e Di- 
deja entrever que el discurso del Tribunal de Justicia iba dirigido no tanto a salvaguardar la posición subjetiva del individuo desde la perspectiva del derecho a la tutela cautelar como a fortalecer al máximo, situado en el plano objetivo de las relaciones ordinamentales, la primacía del ordenamiento jurídico comunitario sobre el interno de los Estados miembros (de hecho también, señalemos una vez más, el Tribunal no dudó en presentar Factortame como una prolongación natural de Simmenthal).

En segundo lugar, muy particular fue la lectura por el Tribunal Supremo, espoleado por El Maestro ${ }^{9}$, del alcance exacto del poder-deber de los jueces nacionales, proclamado en Factortame, de suspender cautelarmente medidas nacionales prima facie contrarias al derecho comunitario. Y es que, en efecto, en ningún momento se refirió el Tribunal de Justicia a los criterios a manejar por dichos jueces a la hora de adoptar tal suspensión: ni se refirió al fumus boni iuris, ni al periculum in mora, ni, en fin, a la ponderación de los intereses en juego. Antes al contrario, su silencio al respecto pareció encubrir una remisión a los derechos nacionales en la línea explícitamente defendida por el abogado general Tesauro, que concluyó su opinión sosteniendo que

«al no existir en esta materia normas comunitarias uniformes, incumbe al ordenamiento jurídico de los Estados miembros regular las modalidades de procedimiento y los requisitos de la tutela cautelar de los derechos reconocidos a los particulares por las normas comunitarias directamente aplicables, siempre que tales modalidades y requisitos no hagan imposible el ejercicio provisional de los derechos alegados y no sean menos favorables que los previstos para proteger los derechos fundados en normas nacionales, por cuanto cualquier disposición o práctica nacional que produjera este efecto resultaría incompatible con el Derecho comunitario».

Tal remisión a los derechos nacionales, por lo demás, sería abiertamente asumida por el propio Tribunal en su Sentencia de 13 de marzo de 2007 (asunto Unibet), y continúa a día de hoy vigente, en espera de una posible revisión por el Tribunal de Justicia de su concepción de las medidas cautelares, desde la perspectiva no tanto de la primacía del derecho de la Unión como de la tutela judicial efectiva en la actualidad consagrada en el art. 47 de la Carta de los Derechos Fundamentales de la Unión, que obligaría a una homogeneización de los criterios para

ritto comunitario, Atti del Seminario avoltosi in Roma, Palazzo della Consulta, nei giorni 15 e 16 di ottobre (págs. 177 y ss.), Milán: Giuffrè.

9 E. García de EnTERría (1992), La batalla por las medidas cautelares, Madrid: ThomsonCivitas. 
su adopción ${ }^{10}$, hasta el momento limitada a las medidas cautelares a adoptar, frente al derecho de la Unión (y no, por tanto, frente al derecho interno), tanto por el juez europeo como por el juez nacional ${ }^{11}$.

Pero al margen de esta última posibilidad, interesa ahora advertir, en tercer lugar, la utilización del derecho público comunitario (en el ejemplo que nos ocupa, de la justicia administrativa cautelar) por nuestra doctrina y jurisprudencia (de forma, se insiste, no precisamente exacta en atención a su fuente, con un acento sobre el criterio del fumus boni iuris que ni venía impuesto por Luxemburgo, ni allí tenía - ni tiene- el protagonismo que aquí se le quiso dar ${ }^{12}$, hoy muy matizado según se desprende, por citar algún ejemplo reciente, de la Sentencia de la Sala Tercera de 24 de febrero de $2016^{13}$ ) a modo de ius commune, sirviendo como revulsivo para replantear, con carácter general (i.e, al margen del radio de acción del ordenamiento jurídico comunitario), el manejo, hasta ese momento en términos cuanto menos lánguidos, de las medidas cautelares por nuestra jurisdicción contencioso-administrativa; revulsivo que terminaría por encontrar respaldo en el Tribunal Constitucional, que en su Sentencia de Pleno 238/1992, de 17 de diciembre de 1992, llegaría a afirmar lo siguiente: «Ciertamente, el art. 24.1 C.E. no hace referencia alguna a las medidas cautelares ni a la potestad de suspensión. Pero de ello no puede inferirse que quede libre el legislador de todo límite para disponer o no medidas de aquel género o para ordenarlas sin condicionamiento constitucional algu-

10 Habida cuenta de que, según dispone en su art. 51, la Carta obliga no sólo a las instituciones de la Unión, sino también a los Estados miembros «cuando apliquen el Derecho de la Unión».

11 Cfr. Sentencia del Tribunal de Justicia de 21 de febrero de 1991, asunto Zuckerfabrik.

12 Según dispone el art. 160.3 de la versión consolidada (2012) del Reglamento de Procedimiento del Tribunal de Justicia, «las demandas [de suspensión o de medidas provisionales] especificarán el objeto del litigio, las circunstancias que den lugar a la urgencia, así como los antecedentes de hecho y los fundamentos de Derecho que justifiquen a primera vista la concesión de la medida provisional solicitada» (en idénticos términos, cfr. art. 156.3 del Reglamento de Procedimiento del Tribunal General, de 4 de marzo de 2015). Los criterios del fumus boni iuris y del periculum in mora (a los que en ocasiones la jurisprudencia añade la ponderación de intereses en juego), «son acumulativos, de manera que si alguno de ellos no se cumple, la demanda de medidas cautelares es rechazada», (cfr. K. LenAerTs, I. Maelis y K. Gutman (2014), EU procedural Law, Oxford: Oxford University Press, pág. 592, quienes a continuación puntualizan: «En la práctica, la determinación de la urgencia de la medida provisional resulta a menudo decisiva y los otros criterios o no tienen que ser considerados, o lo son a efectos simplemente subsidiarios»).

13 2517/2015, en la que puede leerse: «Este Tribunal Supremo ha admitido este criterio en algunas resoluciones a veces con gran amplitud, si bien en el actual estado de la jurisprudencia prevalece una doctrina que acentúa sus límites y aconseja prudencia y restricción en su aplicación... En la actualidad la jurisprudencia del Tribunal Supremo admite el criterio de la apariencia de buen derecho, entre otros, en supuestos de nulidad de pleno derecho, siempre que sea manifiesta; de actos dictados en cumplimiento o ejecución de una disposición general declarada nula; de existencia de una sentencia que anula el acto en una anterior instancia aunque no sea firme; de existencia de un criterio reiterado de la jurisprudencia frente al que la Administración opone una resistencia contumaz o de modo muy excepcional, de prosperabilidad ostensible de la demanda». En la misma línea, cfr. el posterior Auto de 3 de mayo (4509/2016). 
no. La tutela judicial ha de ser, por imperativo constitucional, "efectiva", y la medida en que lo sea o no ha de hallarse en la suficiencia de las potestades atribuidas por ley a los órganos del poder judicial para, efectivamente, salvaguardar los intereses o derechos cuya protección se demanda. Por ello, es preciso reiterar ahora lo que afirmamos en nuestra STC 14/1992, esto es, que "la tutela judicial no es tal sin medidas cautelares que aseguren el efectivo cumplimiento de la resolución definitiva que recaiga en el proceso"» (y «en consecuencia», añadiría el Tribunal a continuación, «reconocida por ley la ejecutividad de los actos administrativos, no puede el mismo legislador eliminar de manera absoluta la posibilidad de adoptar medidas cautelares dirigidas a asegurar la efectividad de la Sentencia estimatoria que pudiera dictarse en el proceso contencioso-administrativo; pues con ello, se vendría a privar a los justiciables de una garantía que, por equilibrar y ponderar la incidencia de aquellas prerrogativas, se configura como contenido del derecho a la tutela judicial efectiva»).

Situémonos ahora a finales de la década de los noventa; concretamente, en el día 13 de enero de 1999, fecha de adopción de la Ley 4/1999, de modificación de la Ley 30/1992, de 26 de noviembre, de Régimen Jurídico de las Administraciones Públicas y del Procedimiento Administrativo Común.

En su Exposición de Motivos, la Ley 4/1999 destacaba cómo «en el Título preliminar se introducen dos principios de actuación de las Administraciones públicas, derivados del de seguridad jurídica. Por una parte, el principio de buena fe, aplicado por la jurisprudencia contencioso-administrativa incluso antes de su recepción por el título preliminar del Código Civil. Por otra, el principio, bien conocido en el derecho procedimental administrativo europeo y también recogido por la jurisprudencia contencioso-administrativa, de la confianza legítima de los ciudadanos en que la actuación de las Administraciones públicas no puede ser alterada arbitrariamente».

Veamos brevemente la historia de la incorporación de este último principio de confianza legítima en nuestro derecho positivo, hoy recogido en el apartado 1 e) del art. 3 de la Ley 40/2015, de 1 de octubre, de Régimen Jurídico del Sector Público.

Dicho principio, bien conocido en los ordenamientos jurídicos alemán y holandés ${ }^{14}$, fue en un determinado momento asumido por el Tri-

14 Cfr. p. e. V. GöTz, «Protection of Legitimate Expectations», y G. TEN BERgE y R. WIDDERSHOvEn, «The Principle of Legitimate Expectations in Dutch Constitutional and Administrative 
bunal de Justicia como propio del ordenamiento jurídico comunitario ${ }^{15}$, lo que implicaba obligación de su respeto no sólo por las instituciones europeas, sino también por los Estados miembros no familiarizados con el mismo, en su faceta de ejecutores del derecho comunitario.

En el caso de España, la confianza legítima fue poco a poco impregnando la mente de los operadores jurídicos, hasta el punto de comenzar a ser invocado ante y aplicado por los tribunales, en sectores por completo ajenos al derecho comunitario.

Así, ya en 1988 el Consejo de Estado, en su «Memoria» correspondiente a dicho año, supo ver las posibilidades que en relación con la confianza legítima ofrecía para nuestro ordenamiento jurídico, tanto dentro como fuera de la vida jurídica comunitarizada, la entonces reciente incorporación a las Comunidades Europeas.

En efecto, haciendo eco de la doctrina constitucional apuntada en relación con la anticipación de la edad de jubilación de jueces y magistrados, considerada en la STC 108/1986, de 29 de junio, como portadora de una "frustración de expectativas existentes y en determinados casos perjuicios económicos que puedan merecer algún género de compensación» ${ }^{16}$, el Consejo de Estado consideró oportuno sugerir «la introducción de categorías dogmáticas intermedias (como la de derechos expectantes, entre derechos plenos consolidados y meras expectativas)», que, «aun no siendo esgrimibles globalmente para obstar el ejercicio de la potestad ordenadora, sí pueden serlo algunas de sus manifestaciones - por conexión con otros derechos o por inocuidad respecto del efecto reformador pretendido- y deben ser medidos e indemnizados cuando la acción pública -incluida la del legislador-comporte efectos privativos o sacrificios individualizables que, si resultaren requeridos por el interés público, a la comunidad, en cuanto beneficiaria de la satisfacción de tal interés, corresponde reparar».

Sugerido lo cual, el Consejo de Estado, tras advertir que al fin indicado podía acreditar «especial relevancia y fecundidad» el principio de confianza legítima, elevado a la categoría de principio general europeo por el Tribunal de Justicia, puntualizó lo siguiente: «No es, desde luego, un principio de valor absoluto capaz de bloquear todo intento de modificación o reforma; pero sí protege eficazmente frente al cambio brusco

Law», en German and Netherlands Reports, presented to the XV International Congress on Comparative Law (Bristol, 26 July to 1 August 1998).

15 Asunto Lemmerz-Werke, Sentencia de 13 de julio de 1965.

16 Cfr. asimismo la STC 99/1987, de 11 de junio. La STC 70/1988, de 19 de abril, orientaría por su parte las posibles medidas compensatorias hacia un tratamiento en el régimen de clases pasivas (al impedir el anticipo de la edad de jubilación alcanzar el número de años de servicio necesario para obtener el haber regulador), 
y por sorpresa, frente a la alteración sensible de una situación en cuya durabilidad podía legítimamente confiarse, sin dar tiempo ni medios al afectado para reequilibrar su posición o adaptarse a la nueva situación». Y añadió: «Este principio tiene un carácter general —aunque suela operar con preferencia en el campo económico y en el funcionarial-, está vinculado a los principios de seguridad jurídica, buena fe, interdicción de la arbitrariedad y otros, con los que suele combinarse y, por supuesto, no exige la preexistencia de derechos subjetivos perfectos, que tienen otras vías de protección» ${ }^{17}$.

No se quedó atrás ni la doctrina (en la misma línea que el Consejo de Estado se pronunciaban García de Enterría y Tomás Ramón Fernández en 1989, en la quinta edición de su Curso de Derecho Administrativo $I$, p. 88), ni la jurisdicción contencioso-administrativa, con el Tribunal Supremo recordando en 1991 (Sentencia de 7 de octubre) ${ }^{18}$ que «el principio constitucional de seguridad jurídica no puede defraudar el principio jurisprudencial de confianza legítima proclamado por el Tribunal de Justicia de la Comunidad Europea y asumido por la jurisprudencia de esta Sala que ahora enjuicia» ${ }^{19}$.

La confianza legítima, volvería a insistir el Consejo de Estado en su «Memoria» correspondiente al año 1994 (pág. 178), es un principio que, «invocado originariamente por la jurisprudencia alemana, asumido después por el Tribunal de Justicia de las Comunidades Europeas y aceptado también por nuestro Tribunal Supremo, tiene por objeto proteger

17 Cfr. la citada «Memoria», pág. 82.

18 Siguiendo la estela marcada por las Sentencias de 26 de enero de 1990, 1 de febrero de 1990 y 1 de marzo de 1991.

19 Ya antes y como ejemplo, las Sentencias de 25 de junio de 1987 y de 20 de junio de 1988, sin referencia alguna a la jurisprudencia comunitaria, habían declarado la necesidad de proteger las expectativas generadas por una normativa dirigida a estimular, bajo promesa - profusamente publicitada - de otorgamiento — sin limitaciones cuantitativas - de incentivos, a las empresas que procedieran a contratar a trabajadores en situación de desempleo. Christopher Forsyth, por su parte, comparte la siguiente anécdota en relación con la irrupción del principio de confianza legítima en el mundo jurídico anglosajón de la mano de Lord Denning en Schmidt v. Secretary of State for Home Affairs (1968): "En un trabajo que publiqué en 1988, sugería que el concepto alemán de protección de la confianza legítima (Vertrauenschutz) había desempeñado su papel en el desarrollo de las expectativas legítimas en derecho inglés, y que ello era un ejemplo de cross fertilization entre sistemas jurídicos. Cometí entonces el error de escribir a Lord Denning para preguntarle acerca de cuanta influencia habría tenido dicho principio en su pronunciamiento en Schmidt v. Secretary of State for Home Affairs, donde, por vez primera, se introdujeron las expectativas legítimas en el derecho inglés... sin cita de autoridad alguna. Me respondió de inmediato diciéndome que estaba seguro de que la idea había salido de su propia cabeza y no de cualquier otra fuente. Así que el origen del concepto, por lo que respecta al derecho inglés, se encontraba solo y exclusivamente en la célebre — con toda justicia- mente creativa de Lord Denning! Ello no significaba que la protección de la confianza legítima debiera excluirse como justificación, pero se trataba de un comienzo poco prometedor!» (cfr. CH. Forsyth (2011), Legitimate Expectations Revisited, Administrative Law Bar Asssociation Summer Conference, 29 May 2011). 
a los interesados, aunque no ostenten verdaderos derechos adquiridos, frente a la alteración brusca de una situación en cuya durabilidad podía legítimamente confiarse». Y añadió, no sin antes dejar de recordar nuevamente su vinculación con otros principios enunciados en el art. 9.3 de la Constitución: «No se quiebra ese principio cuando se tiene conocimiento de la medida invocadora con tiempo suficiente para adaptarse a ella o cuando se establecen en la misma compensaciones adecuadas; se quebraría, en cambio, el principio de confianza legítima si la medida adoptada - que supone un cambio radical de régimen - se aplicara de inmediato y no fuera previsible ni consecuente con el sistema en el que se integra».

En fin, y como adelantaba, el propio legislador terminaría por incorporar dicho principio, en términos ya de auténtico ius proprium positivizado, y por lo que al comportamiento de la Administración pública se refiere, en la Ley $4 / 1999^{20}$.

De nuevo, al igual que sucedió en el terreno de las medidas cautelares, un principio de derecho público europeo, en este caso el de confianza legítima ${ }^{21}$, sirvió, a modo inicialmente de ius commune, para potenciar, en radios internos de acción ajenos a la hoy Unión Europea, la protección de determinadas expectativas - legítimas - hasta ese momento descuidadas en nuestro ordenamiento jurídico ${ }^{22}$. Y una vez incorporado

20 La STS de 15 de noviembre de 1999 (306/1997) nos recuerda cómo llegado el momento de su positivización, la confianza legítima era ya un principio perfectamente asentado en la jurisprudencia, la cual podía sintetizarse en los siguientes puntos: «a) El principio de la confianza legítima, que tiene su origen en el derecho administrativo alemán, ha sido reiteradamente asumido por la jurisprudencia del Tribunal de Justicia de las Comunidades Europeas [...], y, en este sentido forma parte del acervo que integra el derecho comunitario europeo, en el que los principios generales ocupan un lugar especialmente destacado. b) El principio resulta especialmente aplicable cuando se basa en signos externos producidos por la Administración suficientemente concluyentes, unido a unos perjuicios que razonablemente se cree que no se iban a producir (SSTS 28 de julio de 1997 y 23 de mayo de 1998). c) La virtualidad del principio puede comportar la anulación de la norma o del acto y, cuando menos, obliga a responder de la alteración (producida sin conocimiento anticipado, sin medidas transitorias suficientes para que los sujetos puedan acomodar su conducta económica y proporcionadas al interés público en juego, y sin las debidas medidas correctoras o compensatorias) de las circunstancias económicas habituales y estables, generadoras de esperanzas fundadas de mantenimiento. Aunque el principio de confianza legítima no garantiza a los agentes económicos la perpetuación de la situación existente, la cual puede ser modificada, ni les reconoce un derecho adquirido al mantenimiento de una determinada ventaja (SSTS 17 de febrero de 1998 y 19 de julio de 1999. d) En la aplicabilidad del principio han de ponderarse, además de la previsión del régimen transitorio y de la presencia de un interés público perentorio, el conocimiento previo de la medida y su previsibilidad (STS 13 de julio de 1999)».

21 Sobre su utilización en el ámbito del derecho privado, cfr. p. e., recientemente y en nuestro entorno, vinculándola con la doctrina de los actos propios, la Sentencia del Tribunal Supremo (Sala Primera) de 5 de mayo de 2016 (105/2014). En el ámbito anglosajón, cfr. p. e. J. CARTwRIGHT (2006), Protecting Legitimate Expectations and Estoppel in English Law, report to the XVII International Congress on Comparative Law (Utrecht, 16 to 22 July 2006).

22 Hay que tener en cuenta que el principio de confianza legítima comprende diversas vertientes, algunas de las cuales estaban ya presentes en la Ley 30/1992 antes de la reforma de 
como ius proprium, ha servido para fortalecer alguna de sus ramificaciones formales, como la participación ciudadana en el procedimiento de elaboración de normas ${ }^{23}$, reforzada por la Ley 39/2015, de 1 de octubre, del Procedimiento Administrativo Común ${ }^{24}$ (de entre cuyas principales novedades, su Exposición de Motivos destaca la «necesidad de recabar, con carácter previo a la elaboración de la norma, la opinión de ciudadanos y empresas acerca de los problemas que se pretenden solucionar con la iniciativa, la necesidad y oportunidad de su aprobación, los objetivos de la norma y las posibles soluciones alternativas regulatorias y no regulatorias», en un intento de mejorar la participación a la que se refiere el art. 105 de la Constitución, adelantando la intervención de los particulares a la existencia misma de un borrador normativo con el fin de facilitar una captación de opiniones que, vertidas sobre un texto ya redactado, resultan como regla general más difíciles de asumir).

Y de nuevo también, como sucede con el resto de los principios generales de derecho europeo que van siendo elaborados y perfeccionados en Luxemburgo vía pretoriana, habrá que seguir estando atentos a la evolución de la confianza legítima en el contexto global de la Unión, esto es, incluidos los ordenamientos jurídicos de los Estados miembros ${ }^{25}$.

En España, y retomando la doctrina constitucional sobre la confianza legítima y la actividad del legislador, en este caso de urgencia, cabe destacar la reciente STC 270/2015, de 17 de diciembre, en relación con las energías renovables (concretamente, en relación con la producción de energía eléctrica mediante tecnología solar fotovoltaica). En ella, y trayendo a colación la categoría del «operador económico prudente y diligente» que ya manejara el Tribunal de Justicia en su Sentencia de 1 de febrero de 1978 (asunto Lührs), el Tribunal Constitucional, confluyendo con la doctrina del Tribunal Supremo ${ }^{26}$, ensanchó al máximo el

1999 (cfr., p. e., las enunciadas por F. SAInz Moreno (1994), «Buena Fe, Derecho Administrativo» en A. Montoya Melgar (dir.), Enciclopedia Jurídica Básica, vol. I (págs. 829-830), Madrid: Civitas).

23 Sobre la consulta como expectativa formal y su vinculación con las expectativas sustantivas, cfr., en derecho anglosajón, las consideraciones del juez John Laws en $R$ (Bhatt Murphy) v. Independent Assessor [2008] EWCA Civ 755.

24 Cfr. su art. 133

25 La editorial Hart Publishing, por ejemplo, anuncia al respecto la próxima publicación del volumen de A. K. Sperr y D. Hohenlohe-Oehrigen (coords.), The Protection of Legitimate Expectations in Administrative Law: A Comparative Study. En cuanto a su evolución en la jurisprudencia del Tribunal de Justicia, puede verse, recientemente y en nuestra doctrina, el trabajo de C. Jiménez Piernas y F. J. Pascual Vives (2015), «La tutela judicial del principio de protección de la confianza legítima en el Derecho de la Unión Europea», en Riesgo regulatorio en las energías renovables (págs. 73 y ss.), Madrid: Thomson Reuters Aranzadi.

26 «Los agentes u operadores privados que renuncian al mercado, aunque lo hagan más o menos inducidos por una retribución generosa que les ofrece el marco regulatorio, sin la contrapartida de la asunción de riesgos significativos, sabían o debían saber que dicho 
concepto de «riesgo regulatorio» 27 a los efectos de marcar los límites de una confianza legítima ${ }^{28}$ que, sin embargo y en relación con un sistema nacional (sueco) de apoyo a la energía verde, había sido abordada por el Tribunal de Justicia, en su Sentencia de 1 de julio de 2014 (asunto Vindkraft), en los siguientes términos: «El sistema de apoyo a la energía verde cuyo coste de producción es, como han recordado concretamente el Gobierno sueco y la Comisión, todavía bastante elevado en comparación con el de la electricidad producida a partir de fuentes de energía no renovables, tiene por objeto, en esencia, favorecer, en una perspectiva a largo plazo, inversiones en nuevas instalaciones, dando a los productores determinadas garantías en cuanto al desarrollo futuro de su producción de electricidad verde. De este modo, la efectividad de tal sistema requiere, por definición, una cierta permanencia que permita concretamente garantizar el respeto de la confianza legítima de los inversores que se han comprometido en esta vía y asegurar la continuidad de la explotación de estas instalaciones» ${ }^{29}$.

Así como los referidos ejemplos de la justicia cautelar y de la confianza legítima resultan ilustrativos acerca del rol del derecho de la Unión en cuanto ius commune a los efectos de fortalecer la posición jurídica del administrado (sin perjuicio de que el entusiasmo «importador» inicial

marco regulatorio, de carácter público, aprobado en un determinado momento, del mismo modo que era coherente con las condiciones del escenario económico entonces vigente y con las previsiones de demanda eléctrica realizadas entonces, no podía ulteriormente ser ajeno a las modificaciones relevantes de los datos económicos de base, ante las cuales es lógica la reacción de los poderes públicos para acompasarlo a las nuevas circunstancias» (STS de 13 de enero de 2014, 357/2012).

27 Que ya había manejado nuestro Tribunal Supremo en su pionera Sentencia de 11 de junio de 2001, en relación con los costes de transición a la competencia en el sector de la energía.

${ }^{28}$ Hasta el punto, se ha llegado a sostener, de que «con esta doctrina jurisprudencial se ha consagrado una especie de principio de inseguridad jurídica (puesto que nada impide que las normas puedan ser cambiadas de manera vertiginosa e incesante) y de desconfianza legítima (la diligencia exigible al beneficiario de una tarifa regulada le debe llevar a no confiar en su mantenimiento)»: cfr. J. F. Alenza GARcía (2016), "Las energías renovables ante la fugacidad legislativa: la mitificación de los principios de (in)seguridad jurídica y de (des) confianza legítima: a propósito de la STC 270/2015 sobre el nuevo sistema retributivo de las energías renovables», Actualidad Jurídica Ambiental, 55, pág. 4.

${ }_{29} \mathrm{Al}$ margen de las energías renovables, cabe asimismo confrontar, por ejemplo, la aproximación general que, con relación a las modificaciones legislativas repentinas, realizan el TC portugués y el TC español: mientras que para aquél «la afectación de expectativas, en sentido desfavorable, será inadmisible cuando constituya una mutación del ordenamiento jurídico con la que los destinatarios de normas constantes no podían razonablemente contar» (STC $862 / 2013$, de 19 de diciembre), para nuestro TC solamente en casos de modificaciones «absolutamente imprevisibles» estaría la puerta abierta a una posible vulneración de la confianza legítima (STC 81/2015, de 30 de abril). 
haya dado paso a un cierto enfriamiento con el transcurso del tiempo ${ }^{30}$ ), así en el ámbito de la responsabilidad del poder público, según paso a exponer, el sistema jurídico de la Unión ha terminado por provocar una evolución de nuestras reglas de responsabilidad en un sentido inverso, i.e., a los efectos de debilitar la posición jurídica del administrado, cuando menos desde una perspectiva procesal, hasta consolidarse dicho debilitamiento en términos de ius proprium por decisión del legislador del régimen jurídico del sector público. Ello, además y por otro lado, en un confuso contexto en el que resulta dudoso que el manejo del método europeo de responsabilidad como fuente directa de aplicación, i.e., en los radios internos de acción sí cubiertos por el derecho de la Unión, sea conforme con los criterios apuntados desde Luxemburgo.

Comenzando por esta última afirmación, hay que advertir cómo el principio de responsabilidad de los Estados miembros por infracción del derecho de la Unión, por vez primera proclamado por el Tribunal de Justicia en su Sentencia de 19 de noviembre de 1991 (asunto Francovich e.a. $)^{31}$, suele presentarse enmarcado en los siguientes parámetros: desde una perspectiva material (y tal y como hoy recoge, interiorizando la doctrina de Luxemburgo, el art. 32.5 — sobre el que volveremos- de la Ley 40/2015, de Régimen Jurídico del Sector Público), la infracción, para poder generar responsabilidad, ha de ser de una norma que tenga por objeto conferir derechos a los particulares y ha de resultar «suficientemente caracterizada», a lo que debe añadirse, en tercer lugar, la exigencia de una relación de causalidad directa entre la infracción y el daño sufrido; y desde una perspectiva formal, las reglas que presiden esta acción de responsabilidad, a ventilar ante los tribunales internos (auxiliados en su caso vía prejudicial por el Tribunal de Justicia), más allá de las condiciones sustantivas recién mencionadas que derivan del

\footnotetext{
${ }^{30}$ Hasta el punto, en el caso de la justicia cautelar, de la supresión por la LJCA de 1998 «de todo apoyo normativo al criterio del fumus boni iuris, cuya aplicación queda confiada a esta jurisprudencia», i.e., del propio Tribunal Supremo, que continuó advirtiendo en esta Sentencia, antes citada, de 24 de febrero de 2016: «Se elimina, en efecto, del Proyecto LJCA el precepto que disponía que "la adopción de las medidas cautelares podrá acordarse cuando existan dudas razonables sobre la legalidad de la actividad administrativa a que se refieran" (art. 124.2 Proyecto LJCA). En su lugar, la LJCA dispone que «previa valoración circunstanciada de todos los intereses en conflicto, la medida cautelar podrá acordarse únicamente cuando la ejecución del acto o la aplicación de la disposición pudieran hacer perder su finalidad legítima al recurso» (art. 130.1 LJCA). El sentido restrictivo de esta omisión respecto al criterio de fumus boni iuris resulta subrayado por la palabra "únicamente"».

31 Al margen de que tuviésemos que esperar a 1996 (concretamente, a la Sentencia de 5 de marzo de 1996, en los asuntos acumulados Braserie du Pêcheur y Factortame), para empezar a contar con un verdadero régimen de responsabilidad que, en otras cosas, matizaría de manera importante, por la vía conceptual de la «violación suficientemente caracterizada», el régimen de corte objetivo al que parecía apuntar Francovich.
} 
régimen europeo, son las nacionales ${ }^{32}$, siempre y cuando respeten los principios de equivalencia (tales reglas no pueden ser menos favorables que las que presiden las acciones basadas en puro derecho interno) y efectividad (no pueden hacer imposible o excesivamente difícil el derecho de reparación).

Sucede, sin embargo, que tal presentación no es del todo exacta ni correcta, habida cuenta de que, también en relación con las exigencias materiales o sustantivas, el Tribunal de Justicia, fallando en Gran Sala, remite a los derechos nacionales en los siguientes términos: "los tres requisitos [i.e., cuando se haya acreditado que la norma jurídica violada tiene por objeto conferir derechos a los particulares y exista una relación de causalidad entre la violación suficientemente caracterizada alegada y el daño sufrido por el interesado] son necesarios y suficientes para generar, en favor de los particulares, un derecho a obtener reparación, sin excluir, no obstante, que, con arreglo al derecho nacional, el Estado pueda incurrir en responsabilidad en virtud de requisitos menos restrictivos» (doctrina sentada en 1996 en los asuntos acumulados Braserie du Pêcheur y Factortame, y reiterada, entre otras, por la Sentencia de 17 de abril de 2007, asunto A.G.M.-COS.MET).

Partiendo de tal premisa, la Cour de Cassation belga, en su Sentencia de 14 de enero de $2000^{33}$, y tras advertir (en el marco de una acción de responsabilidad ejercitada contra el Estado por no haber permitido, vulnerando el principio de libre circulación de mercancías, la homologación de autocares procedentes de otros Estados miembros) que constituía «una falta en el sentido de los arts. 1382 y 1383 del Código Civil, susceptible de generar la responsabilidad civil de su autor si la misma causa un daño, todo acto u omisión que vulnere una norma de Derecho internacional dotada de efecto directo o una norma de Derecho interno que imponga a los sujetos de Derecho una acción o una abstención de manera determinada», declaró que "no es necesario sobre la base de los arts. 1382 y 1383 del Código Civil, para generar la responsabilidad del poder ejecutivo en el ejercicio de su potestad reglamentaria y como consecuencia de la violación de una norma de derecho internacional - como una disposición directamente aplicable del Tratado $\mathrm{CE}$ - , que

32 Incluidas las concernientes «a la forma y al procedimiento de cálculo de la reparación del daño» (Sentencia del Tribunal de Justicia de 25 de noviembre de 2010, asunto Fuß) y «a la autoridad pública responsable» en el caso de Estados descentralizados en los que determinadas competencias legislativas o administrativas son ejercidas por entidades territoriales dotadas de cierta autonomía o por cualquier otro organismo de derecho público jurídicamente distinto del Estado (Sentencias de 1 de junio de 1999 y de 4 de julio de 2000, asuntos Konle y Haim).

33 Cass., 14 janvier 2000, R.W. 2001-2002, 1906. 
dicha violación sea, además, suficientemente caracterizada, por mucho que tal exigencia sea requerida por el Tribunal de Justicia para generar, en el ordenamiento jurídico comunitario, la responsabilidad de las autoridades comunitarias o de los Estados miembros por violación del derecho comunitario» ${ }^{34}$.

No ha sido ese, sin embargo, el camino seguido hasta el momento en nuestro país, donde tanto el Tribunal Supremo como el Consejo de Estado han excluido la posibilidad de desplazar el régimen europeo de responsabilidad por el —por hipótesis—régimen interno más favorable: el Consejo, argumentando, sin mayor profundidad, que nuestro requisito de la antijuricidad no es menos restrictivo que el de la violación suficientemente caracterizada; el Supremo, sustentando la imposibilidad de aplicar el régimen nacional en la ausencia de similitud de los supuestos abordados por ambas acciones de responsabilidad, frente a leyes inconstitucionales y frente a leyes antieuropeas (similitud que, en su opinión, sería conditio sine qua non para proceder a un análisis comparativo de regímenes en orden a la elección del más generoso para el administrado).

$\mathrm{Al}$ margen de las bondades de tales razonamientos, sobre los que volveremos ${ }^{35}$, interesa por el momento aclarar que la cuestión apuntada atañe no al manejo del derecho de la Unión en cuanto ius commune, sino a su manejo en cuanto fuente directa, impuesta en virtud de nuestra pertenencia a la Unión, i.e., de obligada toma en consideración por los Estados miembros, incluida España, en la medida en que estarían actuando dentro del radio de acción de la Unión (el régimen europeo de responsabilidad al que nos venimos refiriendo es el aplicable, recordemos, a los daños y perjuicios derivados de infracciones del derecho de la Unión tanto por la Unión como por sus Estados miembros).

Cuestión distinta aunque no ajena a la anterior, y que pasamos a abordar, es la incidencia que el régimen europeo de responsabilidad haya podido tener en nuestro propio régimen al margen de imposiciones derivadas de nuestra pertenencia a la Unión, i.e., en el contexto de los daños y perjuicios que los poderes públicos españoles puedan ocasionar a los particulares por acciones u omisiones extrañas al derecho de la Unión; incidencia que, adelanto ya, se ha producido en términos vinculados no tanto con la naturaleza de la infracción que estaría en el origen del daño

34 Sobre la extensión o no de tal doctrina al ámbito de la responsabilidad del Estado legislador, puede verse F. BouHon (2007), "Arrêt d'espèce ou arrêt de principe? Réflexions de synthèse autour de la décision de la Cour de cassation du 28 septembre 2006", Revue Belge de Droit Constitutionnel, 4 , págs. 387 y ss.

35 Cfr. al respecto el reciente y esclarecedor trabajo de E. CoBreros (2015), Responsabilidad del Estado por incumplimiento del Derecho de la Unión Europea, Madrid: Iustel, págs. 205 y ss. 
(no ha habido hasta el momento supuestos, salvo error por mi parte, en que la cualificación de dicha infracción como «suficientemente caracterizada» se haya exigido por nuestros tribunales a los efectos de admitir responsabilidades por acciones $\mathrm{u}$ omisiones vinculadas estrictamente al derecho interno, o lo que es igual, al margen del derecho de la Unión), como con el comportamiento de la víctima del daño.

Es el momento, pues, de traer a colación el asunto Transportes Urbanos, en el que, en respuesta a una cuestión prejudicial planteada por el Tribunal Supremo, el Tribunal de Justicia, mediante Sentencia de 26 de enero de 2010, declaró contraria al derecho de la Unión la doctrina del propio Tribunal Supremo que otorgaba un trato menos favorable al administrado en relación con las acciones de responsabilidad por leyes antieuropeas, si comparado con el régimen aplicable a las acciones de responsabilidad por leyes inconstitucionales: «El Derecho de la Unión», falló el Tribunal de Justicia, "se opone a la aplicación de una regla de un Estado miembro en virtud de la cual una reclamación de responsabilidad patrimonial del Estado basada en una infracción de dicho Derecho por una ley nacional declarada mediante Sentencia del Tribunal de Justicia dictada con arreglo al art. $226 \mathrm{CE}$ [actual $258 \mathrm{TFUE}$ ] sólo puede estimarse si el demandante ha agotado previamente todas las vías de recurso internas dirigidas a impugnar la validez del acto administrativo lesivo dictado sobre la base de dicha ley, mientras que tal regla no es de aplicación a una reclamación de responsabilidad patrimonial del Estado fundamentada en la infracción de la Constitución por la misma ley declarada por el órgano jurisdiccional competente».

Aun sin profundizar en este pronunciamiento, muy comentado dentro y fuera de nuestras fronteras, sí que interesa destacar cómo el principal argumento esgrimido por el Tribunal Supremo para decantarse por la no extensión del más favorable régimen procesal de responsabilidad por leyes inconstitucionales al terreno de las leyes «antieuropeas», a saber, la ausencia de similitud entre ambos supuestos, fue rechazado en Luxemburgo sobre la base de que la única diferencia reseñable entre las reclamaciones basadas en sendos regímenes, consistente en que las infracciones jurídicas en que se sustentarían habrían sido declaradas, en un caso, por el Tribunal Constitucional, y en el otro, por una Sentencia del Tribunal de Justicia, no bastaría para establecer una distinción de régimen entre ambas reclamaciones a la luz del principio de equivalencia. Lo cual no deja de ser un antecedente importante a los efectos de 
analizar las bondades del razonamiento del mismo Tribunal Supremo, ya apuntado, acerca de la imposibilidad siquiera de comparar el criterio interno de la «antijuricidad» con el europeo de la «caracterización suficiente» de la infracción.

También interesa destacar, por otro lado, que una vez recibida la respuesta del Tribunal de Justicia, nuestro Tribunal Supremo no estaba inexorablemente obligado, como sin embargo haría en su Sentencia de 17 de septiembre de $2010^{36}$, a extender su doctrina sobre las leyes inconstitucionales al contexto de las leyes antieuropeas. Y ello porque, como se advirtió en su momento ${ }^{37}$, bien habría podido optar por modificar su propia doctrina acerca de las acciones de responsabilidad por leyes inconstitucionales (lo que no hizo en su Sentencia de Pleno de 2 de junio de $2010^{38}$ ) a los efectos de condicionar su ejercicio, y también el de las acciones de responsabilidad por leyes antieuropeas, al previo agotamiento de los recursos disponibles frente a los actos de aplicación de unas y otras.

Tal operación, que aun resultando desfavorable para el administrado, no dejaría de respetar tanto el principio de equivalencia ${ }^{39}$ como, parece, el de efectividad ${ }^{40}$, sería finalmente practicada por la Ley 40/2015, al disponer en los apartados 4 y 5 de su art. 32 que si la lesión es consecuencia de la aplicación de una ley declarada inconstitucional o de norma declarada contraria al derecho de la Unión Europea, procederá su indemnización cuando el particular haya obtenido, en cualquier ins-

$36153 / 2007$.

37 Cfr. la contribución de C. Plaza (2012), «Un viaje de ida y vuelta en transportes urbanos: responsabilidad patrimonial del Estado legislador y principio de equivalencia (sobre la Sentencia del Tribunal de Justicia de la UE de 10 de enero de 2010 y la Sentencia del Tribunal Supremo de 17 de septiembre de 2010)», en Liber Amicorum T. R. Fernández, vol. II (pág. 3535), Madrid: Thomson Reuters Civitas.

$38588 / 2008$.

39 Al quedar sometidas ambas acciones de responsabilidad a la mismas reglas de procedibilidad, y teniendo en cuenta que, como señaló el Tribunal de Justicia en el mismo Transportes Urbanos en relación con el alcance del principio de equivalencia finalmente invocado para sustentar la incompatibilidad de la doctrina del Tribunal Supremo con el derecho de la Unión, que «este principio no puede interpretarse en el sentido de que obliga a un Estado miembro a extender su régimen interno más favorable a todos los recursos interpuestos en un ámbito determinado del derecho».

40 Si bien el Tribunal de Justicia consideró que una vez declarada, sobre la base del principio de equivalencia, la incompatibilidad de la doctrina del Tribunal Supremo con el derecho de la Unión, ya no resultaba necesario examinar la regla del agotamiento previo de las vías de recurso a la luz del principio de efectividad, sí que se pronunció al respecto el abogado general del caso Poiares Maduro, sosteniendo que «la subordinación de la admisibilidad de la acción de responsabilidad del Estado por infracción legislativa del derecho comunitario al requisito de que la persona afectada haya atacado previamente el acto administrativo basado en dicha ley no es, en principio, contraria al principio de efectividad, dado que mediante la impugnación en tiempo oportuno de la validez del acto lesivo, la víctima habría podido obtener reparación por la totalidad del perjuicio invocado». 
tancia, sentencia firme desestimatoria de un recurso contra la actuación administrativa que ocasionó el daño, siempre que, además, se hubiera alegado, respectivamente, la inconstitucionalidad o la infracción del derecho de la Unión Europea posteriormente declarada ${ }^{41}$.

Dicho lo cual, una cosa es que la reciente Ley del Sector Público parezca respetar los referidos principios de equivalencia y efectividad ${ }^{42}$ (por lo demás exigibles, con carácter general, en ausencia o insuficiencia del derecho de la Unión en cuanto a las reglas orgánicas y procedimentales que han de presidir su aplicación en el ámbito interno), y otra distinta asumir que lo mismo sucede con el principio de aplicación del régimen sustantivo más favorable (que, también parece y según vimos, ha de presidir, específicamente, el manejo por el juez nacional de las reglas sustantivas, europeas e internas, de responsabilidad por infracción del Derecho de la Unión).

Así y al pronto, y dejando a un lado el debate acerca de si el régimen español de responsabilidad puramente ad intra (i.e., al margen del radio de acción del derecho de la Unión) es o deja de ser en exceso generoso para con los particulares ${ }^{43}$, está por ver que dicho régimen no sea, como viene sosteniendo el Consejo de Estado, más favorable que el europeo, cuando menos en lo concerniente a la actividad del legislador formal, en relación con la cual el Tribunal Supremo viene identificando la antijuricidad con la mera declaración de inconstitucionalidad ${ }^{44}$, esto es, sin cualificación especial alguna a modo de la "caracterización suficiente» exigida para la declaración de responsabilidad por leyes anti-europeas ${ }^{45}$;

41 Ello en el bien entendido, como ha advertido en diversas ocasiones el Tribunal de Justicia, de que «no se puede supeditar la reparación del daño a la exigencia de que el Tribunal de Justicia haya declarado previamente la existencia de un incumplimiento del Derecho comunitario imputable al Estado» (por todas, Sentencia de 24 de marzo de 2009, asunto Danske Slagterier).

42 Por lo que respecta a la LOPJ y la responsabilidad del Estado-Juez, cfr. la opinión crítica de Edorta Cobreros en su trabajo antes citado, págs. 183 y ss.

43 Cfr. por todos las críticas de O. Mir PuigPelat (2002), La responsabilidad patrimonial de la Administración. Hacia un nuevo sistema, Madrid: Civitas, y E. García De EnTERría (2007), La responsabilidad patrimonial del Estado legislador en el Derecho español, Madrid: Thomson Civitas.

${ }^{44}$ Por más que su ya mencionada Sentencia plenaria de 2 de junio de 2010, tras reafirmar —en un contexto de intenso debate interno - la doctrina — asentada desde el año 2000 — según la cual «en los casos en que el título de imputación de la responsabilidad patrimonial del Estado legislador lo es la posterior declaración de inconstitucionalidad de la ley o norma con fuerza de ley cuya aplicación irrogó el perjuicio, debe imponerse como regla general o de principio la afirmación o reconocimiento de la antijuridicidad de éste», llegara a admitir que "circunstancias singulares, de clara y relevante entidad, podrían, como hipótesis no descartable, llegar a explicar y justificar una afirmación contraria, que aseverara que el perjudicado tuviera el deber jurídico de soportar el daño».

45 El uso que el Tribunal Supremo viene haciendo de la antijuricidad en el ámbito reglamentario, en cambio, sí resultaría más próximo al que el Tribunal de Justicia haría de la naturaleza «suficientemente caracterizada» de la infracción, con el concepto del «margen de 
y otro tanto parece que cabría sostener en relación con la ausencia en nuestro régimen puramente interno de la exigencia, tal y como aparece enunciada en el régimen europeo, de que la infracción se refiera a una norma que tenga "por objeto conferir derechos a los particulares».

En cuanto al argumento de la ausencia de similitud entre las acciones de responsabilidad para proceder a su comparación y, a partir de la misma, a la elección en su caso del régimen sustantivo o material más favorable para el administrado, el Tribunal Supremo, aun manifestando ciertas dudas al respecto, insistiría, en su Sentencia de 22 de septiembre de $2014^{46}$, en diferenciar sendas reclamaciones de responsabilidad, por leyes inconstitucionales y por leyes antieuropeas, a los efectos de eludir el desplazamiento de la "violación suficientemente caracterizada»; y lo haría en unos términos realmente sorprendentes, a la luz del pronunciamiento del Tribunal de Justicia en Transportes Urbanos: «Retomada la deliberación y atendidas las alegaciones de las partes y del Ministerio Fiscal», declaró el Tribunal Supremo, «esta Sala ha llegado al convencimiento de que no existe realmente similitud entre la declaración de inconstitucionalidad de una ley por el Tribunal Constitucional y la estimación de un recurso por incumplimiento por el Tribunal de Justicia de la Unión Europea. Y al no existir verdadera similitud entre ambos supuestos, es claro que el principio de equivalencia y efectividad —sobre cuyo alcance fueron oídas las partes y el Ministerio Fiscal, a efectos del posible planteamiento de cuestión prejudicial- no resulta de aplicación». Tal declaración, como decíamos, no deja de sorprender a la luz de Transportes Urbanos, donde, recordemos, el Tribunal de Justicia, tras constatar que «la única diferencia existente entre las dos reclamaciones mencionadas [basadas en la infracción del derecho de la Unión y en la infracción de la Constitución] consiste en que las infracciones jurídicas en las que se basan han sido declaradas, en un caso, por el Tribunal de Justicia mediante una sentencia dictada con arreglo al art. 226 CE y, en otro, por una Sentencia del Tribunal Constitucional», sostuvo que «esta única circunstancia, a falta de cualquier mención en el auto de remisión de otros elementos que permitan declarar la existencia de otras diferencias entre la reclamación de responsabilidad patrimonial del Estado por infracción del derecho de la Unión y aquella que podría interponerse sobre la base de una infracción de la Constitución declarada por el Tribu-

apreciación» como protagonista en ambos casos (por lo que al Tribunal de Justicia se refiere, permítaseme remitir a R. Alonso (2014), Sistema jurídico de la Unión Europea, Madrid: Thomson Reuters Civitas, págs. 359-362; y en cuanto al Tribunal Supremo, cfr. G. FERNÁNDEZ Farreres (2015), La responsabilidad de la Administración Pública y de otros poderes públicos en el ordenamiento jurídico español, Bogotá: Universidad Sergio Arboleda, págs. 44-46).

46 390/2012. 
nal Constitucional, no basta para establecer una distinción entre ambas reclamaciones a la luz del principio de equivalencia».

Así las cosas, y más allá de que la diferente naturaleza de las acciones de responsabilidad podría quizás llegar a sustentarse en otros criterios, lo cierto es que ni la Ley 40/2015 ha cerrado el debate en torno al posible desplazamiento del régimen europeo de responsabilidad por el - supuestamente- más favorable interno ${ }^{47}$, ni se han explorado todas las virtualidades que en nuestro ordenamiento jurídico podría llegar a desplegar dicho régimen en términos de ius commune, como, por ejemplo, en el terreno de las omisiones normativas generadoras de daños y perjuicios (omisiones que, conviene no olvidar, están en el origen de la proclamación misma de la responsabilidad de los Estados miembros por infracción del Derecho comunitario en Francovich e.a. ${ }^{48}$, y cuyas consecuencias en nuestro ordenamiento, al margen del radio de acción de la Unión, están aún por perfilar ${ }^{49}$ ).

Para otro momento quedan, sin embargo, ulteriores reflexiones al respecto, aprovechando la enriquecedora libre circulación de ideas y técnicas jurídicas que, junto a la libre circulación de mercancías, servicios, capital y trabajo - esencia del mercado interior-, nos aportó hace treinta años nuestro ingreso a la hoy Unión Europea ${ }^{50}$, y sobre la que, en última instancia, debe seguir asentándose la percepción de una conciencia europea, imprescindible para avanzar, como preveía ya el Tratado de la Comunidad en 1957 en la primera frase de su Preámbulo, hacia «una unión cada vez más estrecha entre los pueblos europeos».

47 En contra de tal suposición, por ejemplo, se pronuncia en un reciente e interesante trabajo A. González Alonso (2016), «La responsabilidad del Estado legislador por vulnerar Derecho europeo o la Constitución: un análisis comparativo», Revista Española de Derecho Constitucional, 106, págs. 381-429.

48 Concerniente, recordemos, a las consecuencias de la falta de transposición por Italia de una Directiva relativa a la protección de los trabajadores asalariados en caso de insolvencia del empresario.

49 En relación con las omisiones legislativas, puede verse la aportación del Tribunal Constitucional español, bajo el título Los problemas de la omisión legislativa en la jurisprudencia constitucional (con Juan Luis Requejo como ponente), en la XIV Conferencia de Tribunales Constitucionales Europeos celebrada en Vilna, 2-6 de junio de 2008. En cuanto a las omisiones reglamentarias, cfr. la STS, y la doctrina en ella recogida, de 15 de diciembre de 2015 $(514 / 2013)$

50 Cfr. E. García de Enterría (1994), «Un paso capital en el Derecho constitucional británico: el poder de los jueces para enjuiciar en abstracto y con carácter general las leyes del Parlamento por su contradicción con el Derecho comunitario", Revista de Instituciones Europeas, 3 , pág. 743 . 